UDC 616.24-085.816.2-037-053.2

DOI: $10.15587 / 2519-4798.2020 .213053$

\title{
PROGNOSIS OF DIFFICULT WEANING FROM MECHANICAL VENTILATION IN CHILDREN WITH ACUTE RESPIRATORY FAILURE
}

\section{O. Filyk}

The aim of this study was to determine the significance of factors such as transthyretin levels, right diaphragm thickening fraction, amplitude of left diaphragm dome movements, stroke volume index (SVI), cardiac index (CI), $\mathrm{SpO}_{2} / \mathrm{FiO}_{2}$ ratio and transthyretin/C-reactive protein in unsuccessful weaning from AV in children with various forms of ARF at the stage of weaning from mechanical ventilation (MV).

Materials and methods. We complete the prospective single-center cohort study and enrol 67 patients 1 month18 years old with hypoxemic and hypercapnic-hypoxemic acute respiratory failure $(A R F) .46$ of them need invasive mechanical ventilation (MV) for more than 3 days. We divide them into 1 st group $(n=35$, they were successfully weaned) and 2 nd group ( $n=11$, they need reintubation and $M V$ within the next 48 hours).

We performed ultrasound examination of diaphragm, prolonged non-invasive monitoring of hemodynamic parameters to determine SVI, CI, SpO ${ }_{2}$ with esCCO technology (estimated continuous cardiac output), NIHON COHDEN; determination of transthyretin (TTR) with G-Biosciences/Geno Technology, (USA) kit. Data were recorded on the first day of $M V(d 1)$, on $3 r d$, 5th, 7 th day of treatment $\left(d_{3}, d_{5}, d_{7}\right)$. Logistic regression method was used to make a predictive model of the probability of unsuccessful weaning from $M V$.

Results. We have established (formula 1), that the risk of unsuccessful weaning from MV in patients with hypoxemic ARF increases with low values of transthyretin serum level, right hemidiaphragm thickening fraction, SVI and high CI. $R=-12.008+0.242 \times(T T R, n g / m l)+1.720 \times($ right hemidiaphragm thickening fraction, $\%)+1.711 \times\left(\mathrm{SVI}, \mathrm{ml} / \mathrm{beat} / \mathrm{m}^{2}\right)-$ $-3.120 \times\left(\mathrm{CI}, \mathrm{l} / \mathrm{min} / \mathrm{m}^{2}\right)(1)$.

The risk of unsuccessful weaning from MV in patients with hypercapnic-hypoxemic ARF (formula 2) increases with low values of transthyretin serum level, amplitude of left hemidiaphragm movement, SVI, SpO $2 / \mathrm{FiO}_{2}$ and transthyretin/C-reactive protein ratio.

$R=-42.233+0.389 \times($ TTR,$n g / m l)+22.189 \times($ amplitudeoflefthemidiaphragmmovement, $m m)+1.120 \times\left(\mathrm{SpO}_{2} / \mathrm{FiO}_{2}\right)+$ $+2,885 \times\left(\mathrm{SVI}, \mathrm{ml} / \mathrm{beat} / \mathrm{m}^{2}\right)+14.944 \times(T T R / C R P)(2)$.

Conclusions. The level of transthyretin and SVI in addition to the indicators of thickening fraction of right hemidiaphragm and CI in children with hypoxemic ARF and the amplitude of left hemidiaphragm movements, ratios $\mathrm{SpO}_{2} / \mathrm{FiO}_{2}$ and transthyretin/C-reactive protein in children with hypercapnic-hypoxemic ARF might affect the process of weaning from $M V$. Thus, acute malnutrition with diaphragmatic dysfunction and hyperdynamic type of blood circulation reduce the likelihood of successful weaning from MV and worsen clinical outcome in children with different types of ARF

Keywords: children, acute respiratory failure, prognosis of weaning from $M V$

Copyright (C) 2020, O. Filyk.

This is an open access article under the CC BY license (http://creativecommons.org/licenses/by/4.0).

\section{Introduction}

$30-64 \%$ of children in intensive care units require mechanical ventilation (MV) due to the presence of various forms of acute respiratory failure (ARF) [1]. The frequency of unsuccessful weaning from MV in children $0-18$ years is from $6.2 \%$ [2] to $36 \%$ [3]. Factors associated with unsuccessful weaning from MV are associated with both the anatomical and physiological features of the respiratory system in children and comorbidities, including cardiovascular disorders [4], and the child's state of health before admission to intensive care unit (ICU), and may also occur during treatment due to providing of respiratory therapy therapy [5]. And if there are recommendations for adult patients [6], then in the treatment of children intensive care physicians use both recommendations for adult patients and their own clinical judgment, taking into account the dynamics of the patient, the presence of comorbidities and correction of basic physiological parameters.
The aim of this study was to determine the significance of factors such as transthyretin levels, right diaphragm thinning fraction, amplitude of left diaphragm movements, stroke volume index (SVI), cardiac index (CI), $\mathrm{SpO}_{2} / \mathrm{FiO}_{2}$ ratio and transthyretin/C-reactive protein in unsuccessful weaning from $\mathrm{MV}$ in children with various forms of ARF during weaning from MV.

\section{Materials and methods}

From May 2018 to December 2019, a prospective cohort single-center study was conducted on the clinical basis of the Department of Anesthesiology and Intensive Care of Danylo Halytsky Lviv National Medical University (Department of Anesthesiology and Intensive Care, Municipal Non-Commercial Enterprise, Lviv Regional Children's Clinical Hospital "OCHMATDYT") patients aged 1 month to 18 years. The study was conducted in accordance with the requirements of good clinical prac- 
tice, the Council of Europe Convention on Human Rights and Biomedicine, the Helsinki Declaration of the World Medical Association and approved by the Bioethics Commission of Danylo Halytsky Lviv National Medical University, protocol No. 1 dated 30.01.2018. Informed consent was obtained from the legal representatives of all patients to participate in the study.

The inclusion of patients in the study (Fig. 1) was as follows: during the study, there were admitted 67 patients with acute respiratory failure who required invasive MV. In 7 patients it was impossible to make a reliable measurement of growth due to significant deformities of the musculoskeletal system and severe perinatal injuries of the central nervous system, these patients were not included in the data analysis.

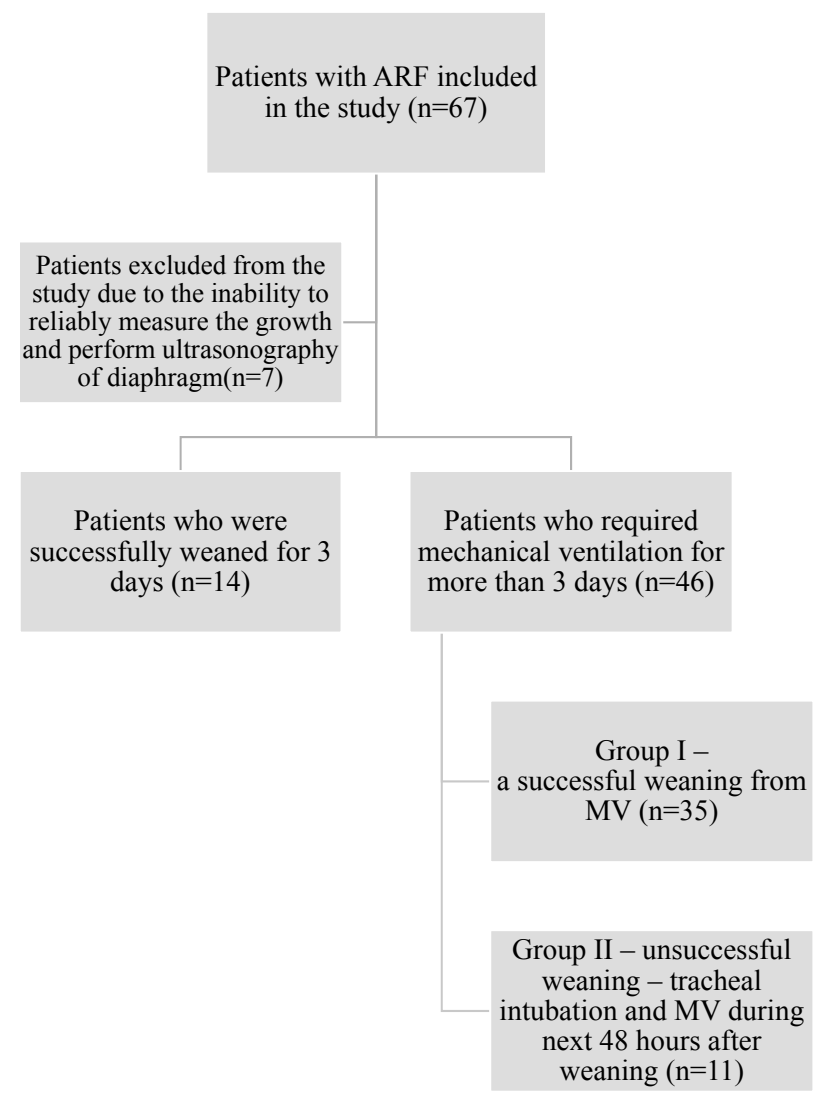

Fig. 1. Admission of patients to the study

Patients were retrospectively divided into those who successfully weaned from MV within the first 3 days after its onset, and patients who required MV for more than 3 days, who in turn were divided into group I patients (successfully weaned from MV) and II group of patients (weaning from AV was unsuccessful, these patients required reintubation for the next $48 \mathrm{~h}$ ) (Fig. 1).

To determine the functioning of the diaphragm used its ultrasound examination during MV in P-SIMV and P-SIMV+ modes of MV, spontaneous breaths were initiated by the patient himself. The fraction of diaphragm thickening, the amplitude of its movements were analyzed, adapting the inspiratory time of the MV device to the frequency and duration of independent contractions of the diaphragm, which allowed to reduce the frequency of dyssynchrony of the patient with the MV device. Prolonged non-invasive monitoring using esCCO (estimated continuous cardiac output) technology was used to determine hemodynamic parameters (heart rate (HR), blood pressure (BP), stroke volume index (SVI) and cardiac index $(\mathrm{CI})$ ) and oxygenation $\left(\mathrm{SpO}_{2}\right)$, NIHON COHDEN. Determination of the level of transthyretin (TTR) was performed using ELISA technology using reagents from G-Biosciences/Geno Technology (USA); The level of C-reactive protein in the blood serum was determined using the "CRP latex kit for qualitative and semi-quantitative determination of C-reactive protein" produced by "Philisit - Diagnostics", according to the instructions provided by the manufacturer. Indicators were recorded at the beginning of MV (d1), on the 3rd, 5th, 7 th day of treatment (d3, d5, d7, respectively).

All patients with pneumonia as a cause of respiratory failure and with a decrease in $\mathrm{paO}_{2}$ level of less than $60 \mathrm{~mm} \mathrm{Hg}$ or a $\mathrm{paO}_{2} / \mathrm{FiO}_{2}$ ratio less than 300 were considered patients with hypoxemic acute respiratory failure. All patients with a combination of acute obstructive bronchitis/bronchiolitis/bronchial asthma and pneumonia with an increase in $\mathrm{paCO}_{2}$ levels above $45-50 \mathrm{~mm}$ $\mathrm{Hg}$ and a decrease in $\mathrm{paO}_{2}$ level less than $60 \mathrm{~mm} \mathrm{Hg}$ or a $\mathrm{paO}_{2} / \mathrm{FiO}_{2}$ ratio less than 300 were considered to have combined hypercapnic-hypoxemic ARF.

Statistical analysis of research results was performed using Microsoft Office for Mac (Excel for Mac analysis package, Version 16.35), Statistica 6 (StatSoft), SPSS Statistics 17.0. All obtained quantitative data wereanalysed by conventional methods of variation statistics using the values of arithmetic mean (M), standard deviation $(\sigma)$, Student's criterion $(t)$, significance level $(p)$. The difference in parameters was considered statistically significant at $\mathrm{p} \leq 0.05$. The logistic regression method was used to build a prognostic model of the probability of unsuccessful weaning from AV. The probability of complications $p$ depending on the factors we selected was calculated by formula (1):

$$
\mathrm{P}=\left(\mathrm{e}^{\mathrm{R}}:\left(1+\mathrm{e}^{\mathrm{R}}\right)\right) \text {, }
$$

where $\mathrm{e}=2.72 \ldots-$ basis of natural logarithms; $\mathrm{R}$ is the value calculated by formula (2):

$$
\mathrm{R}=\mathrm{K}+\beta_{1} \mathrm{x}_{1}+\beta_{2} \mathrm{x}_{2}+\ldots \beta_{\mathrm{n}} \mathrm{x}_{\mathrm{n}}
$$

where $\mathrm{K}-$ constant, $\beta_{\mathrm{i}}-$ coefficients for each factor, $\mathrm{x}_{\mathrm{i}}-$ importance of factors.

The adequacy and probability of the developed mathematical models were performed using Wald's criterion and $\chi^{2}$-distribution (by comparison with the tabular value for the corresponding number of degrees of freedom).

\section{Research results}

After conducting a prospective study, we found that among the 60 patients included in the data analysis, 46 patients (77\%) required MV for more than 3 days, of which 35 patients who were group I (76\%) were successfully weaned from $\mathrm{MV}$, repeated intubation for the next 
48 hours required 11 patients (24\%) who were included in group II.

We analyzed patient demographics (Table 1) and found that the mean age of patients was $8.9 \pm 5.5$ months (median - 4 months), the youngest included in the data analysis was a patient aged 2 months, the oldest - age 11 years (132 months). The sex distribution was dominated by boys $(\mathrm{n}=34 ; 57 \%)$. The body mass index of the patients included in the analysis ranged from $7.2 \mathrm{~kg} / \mathrm{m}^{2}$ to $18.8 \mathrm{~kg} / \mathrm{m}^{2}$.

The median age among group II patients was lower compared to the median age of group I patients (3.2 months and 23.1 months, respectively, $\mathrm{p}=0.003$ ). Therefore, it should be assumed that one of the factors that may affect the success of weaning from MV is the age of the patient.

Table 1

Demographic characteristics of the studied group of patients

\begin{tabular}{|c|c|}
\hline Characteristic & Mean \pm SD \\
\hline Body weight, $\mathrm{kg}$ & $5.9 \pm 2.9$ \\
\hline Height, cm & $70.6 \pm 23.6$ \\
\hline BMI, $\mathrm{kg} / \mathrm{m}^{2}$ & $13.2 \pm 2.5$ \\
\hline
\end{tabular}

Note: $S D$ - standard deviation

The most common reasons for admission to the Department of Anesthesiology and Intensive Care among patients of groups I and II were: pneumonia (22 cases); pneumonia in combination with severe nutritional deficiency (5 cases) or encephalopathy (5 cases), bronchopulmonary dysplasia (3 cases) (Table 2). Cases of unsuccessful weaning from $\mathrm{MV}$ were significantly more common among patients with septic shock $(p=0.02)$ and pneumonia $(p=0.04)$.

Clinical characteristics of the causes of ARF in groups I and II of patients

\begin{tabular}{|c|c|c|c|c|}
\hline $\begin{array}{c}\text { Diagnosis on } \\
\text { admission to } \\
\text { treatment }\end{array}$ & $\begin{array}{c}\text { The total } \\
\text { number } \\
\text { of cases }\end{array}$ & $\begin{array}{c}\text { Group } \\
\text { I, the } \\
\text { number of } \\
\text { cases }\end{array}$ & $\begin{array}{c}\text { Group } \\
\text { II, the } \\
\text { number of } \\
\text { cases }\end{array}$ & $\mathrm{P}^{\mathrm{a}}$ \\
\hline Septic shock & 11 & 8 & 3 & 0.02 \\
\hline Pneumonia & 22 & 16 & 6 & 0.04 \\
\hline $\begin{array}{c}\text { Pneumonia } \\
\text { and nutritional } \\
\text { deficiency }\end{array}$ & 5 & 1 & 4 & $>0.05$ \\
\hline $\begin{array}{c}\text { Pneumonia and } \\
\text { encephalopathy }\end{array}$ & 5 & 2 & 3 & $>0.05$ \\
\hline $\begin{array}{c}\text { Pneumonia and } \\
\text { bronchopulmo- } \\
\text { nary dysplasia }\end{array}$ & 3 & 2 & 1 & $>0.05$ \\
\hline
\end{tabular}

Note: $a$-comparison of groups I and II using the $\chi^{2}$ test

In our study, it was found that SVI at the stage of study $\mathrm{d}_{1}$ in group I patients was $28.8 \pm 2.5 \mathrm{ml} / \mathrm{m}^{2}$, in group II patients $27.1 \pm 3.5 \mathrm{ml} / \mathrm{m}^{2}(\mathrm{p}>0.05)$. However, already at the stages of study $\mathrm{d}_{3}, \mathrm{~d}_{5}$ and $\mathrm{d}_{7}$ (Fig. 2) SVI values in patients of group II were significantly lower than similar indicators among patients of group I, in particular at the stage of study $\mathrm{d}_{3}$ and group of patients SVI was $36.4 \pm 5.1 \mathrm{ml} / \mathrm{m}^{2}$, in group II $-24.1 \pm 2.9 \mathrm{ml} / \mathrm{m}^{2}$ $(\mathrm{p}=0.02)$. However, no differences in this indicator were found among patients of group II between stages of study $\mathrm{d}_{1}$ and $\mathrm{d}_{3}(\mathrm{p}>0.05)$ and no significant differences were found for both groups of patients at stages of study $\mathrm{d}_{3}, \mathrm{~d}_{5}$ and $\mathrm{d}_{7}$.

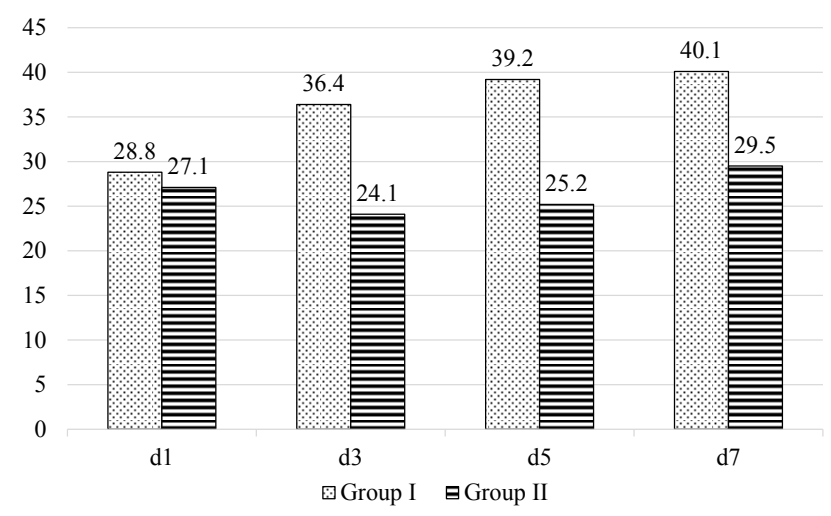

Fig. 2. Dynamics of changes in the stroke volume index $\left(\mathrm{ml} / \mathrm{m}^{2}\right)$ in groups I and II of patients

We analyzed CI values among patients of both groups during the study (Fig. 3) and found that at the stage of study $\mathrm{d}_{1}$ there were no significant differences between the two groups, CI was higher than normal and was in group I $6.8 \pm 0.74 \mathrm{1} / \mathrm{min} / \mathrm{m}^{2}$, in group II $-7.1 \pm$ $\pm 0.92 \mathrm{l} / \mathrm{min} / \mathrm{m}^{2}(\mathrm{p}>0.05)$.

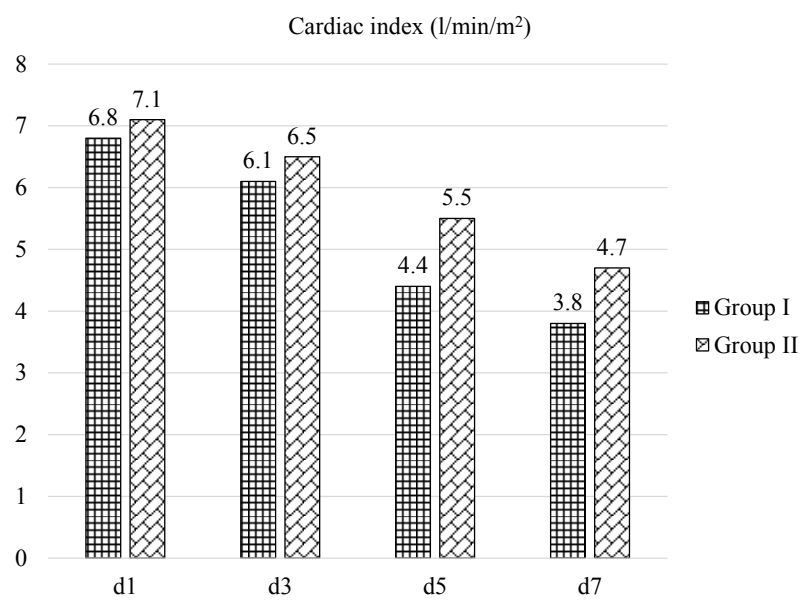

Fig. 3. Dynamics of changes in the cardiac index $\left(1 / \mathrm{min} / \mathrm{m}^{2}\right)$ in groups I and II of patients

Later, starting from the stage of study $\mathrm{d}_{3}$, there was a tendency to a gradual decrease in CI among patients of both groups. In group I at stage $\mathrm{d}_{3} \mathrm{CI}$ was $6.1 \pm 1.2 \mathrm{l} / \mathrm{min} / \mathrm{m}^{2}$, at stage $\mathrm{d}_{5}-4.4 \pm 0.261 / \mathrm{min} / \mathrm{m}^{2}$ and at stage $d_{7}-3.8 \pm 0.621 / \mathrm{min} / \mathrm{m}^{2}$. In the second group of patients at similar stages of the study CI had the following values: $6.5 \pm 0.741 / \mathrm{min} / \mathrm{m}^{2}(\mathrm{p}>0.05)$ at stage $\mathrm{d}_{3} ; 5.5 \pm$ $\pm 0.52 \mathrm{l} / \mathrm{min} / \mathrm{m}^{2}(\mathrm{p}>0.05)$ at stage $\mathrm{d}_{5}$ and $4.7 \pm 0.23 \mathrm{l} / \mathrm{min} / \mathrm{m}^{2}$ $(\mathrm{p}=0.009)$ in step $\mathrm{d}_{7}$, respectively. 
Evidence for the role of nutritional status in weaning from MV includes both the role of muscle mass and the function of the diaphragm as the main respiratory muscle. We analyzed the number of days when there was a decreased level of serum transthyretin (a protein that responds quickly - within 1-2 days to the development of acute nutritional insufficiency) and found that in patients of group II this proportion was higher compared with the share of days in group I patients, and was for group II $37.5 \%$, for group I $11.2 \%(p=0.002)$ (Fig. 4).

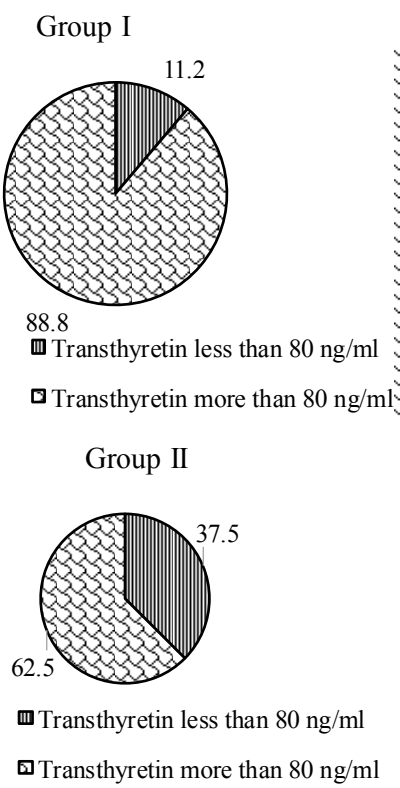

Fig. 4. The time during which transthyretin levels were reduced, relative to the total time of MV among patients of groups I and II, \%

We found that in the second group of patients at stages of study $\mathrm{d}_{3}$ and $\mathrm{d}_{5}$ more often recorded low levels of thickening fraction of the right diaphragm (less than $15 \%$ ) with a detection rate of $78 \%$ at study stage $\mathrm{d}_{3}$ and $59 \%$ at study stage $\mathrm{d}_{5}$, compared with $32 \%$ and $17 \%$ at similar stages of the study among patients of group I. Signs of excessive contraction of the right dome of the diaphragm (thickening fraction over 45-50\%) were in $67 \%$ of patients in group II and only $5 \%$ of patients in group I at study stage $d_{7}(p=0.0001)$.

Using the method of logistic regression, taking into account all the above indicators, based on our developed formula (formula (3)), we found that the risk of unsuccessful weaning from MV in patients with hypoxemic ARF increases at low values of transthyretin in serum, low values fractions of thickening of the right dome of the diaphragm and shock index, high values of the cardiac index.

$\mathrm{R}=-12.008+0.242 \times(\mathrm{TTR}, \mathrm{ng} / \mathrm{ml})+$

$+1.720 \times($ thickening fraction of the right dome of the diaphragm, \%)+1.711 $\times\left(\mathrm{SVI}, \mathrm{ml} / \mathrm{stroke} / \mathrm{m}^{2}\right)-$

$-3.120 \times\left(\mathrm{CI}, 1 / \mathrm{min} / \mathrm{m}^{2}\right)$.

The risk of failed weaning in hypercapnic-hypoxemic ARF (formula (4)) increases at low values of transthyretin levels, the amplitude of movements of the left dome of the diaphragm, $\mathrm{SVI}, \mathrm{SpO}_{2} / \mathrm{FiO}_{2}$ and the ratio of transthyretin/C-reactive protein.

$$
\begin{aligned}
& R=-42,233+0,389 \times(\mathrm{TTR}, \mathrm{ng} / \mathrm{ml})+ \\
& +22,189 \times(\text { amplitude of movements of } \\
& \text { the left dome of a diaphragm, mm })+ \\
& +1,120 \times\left(\mathrm{SpO}_{2} / \mathrm{FiO}_{2}\right)+2,885 \times \\
& \times\left(\mathrm{SVI}, \mathrm{ml} / \mathrm{stroke}^{2} \mathrm{~m}^{2}\right)+14,944 \times(\mathrm{TTR} / \mathrm{CRP}) .
\end{aligned}
$$

\section{Discussion}

Cardiopulmonary interaction is known to be extremely important for the supply of oxygen to all organ systems, the elimination of carbon dioxide and the delivery of nutrients. Insufficient delivery of oxygen to the tissues leads to intense work of the cardiovascular system with an increase in such indicators as cardiac output and cardiac index. The cause of unsuccessful weaning from MV may be reduced CI [6], and the marker of unsuccessful weaning with gradual reduction of parameters MV - CI, higher than physiological values [7]. The high cardiac index reflects the need to increase oxygen delivery and indicates non-cardiogenic genesis of difficult weaning from MV. It is important to remember that as the work of the respiratory muscles increases, the oxygen cost of breathing increases - the higher the level of shortness of breath, the more oxygen is consumed for the work of the muscles and the deficit of its delivery does not change. Cardiovascular dysfunction plays a special role in obstructive respiratory disorders, when the patient has right ventricular failure, which reduces lung perfusion, venous blood delivery to the alveoli and the level of gas exchange [7, 8]. In children, high CI is maintained primarily by increasing heart rate, because myocardial compliance in young children is low and fluid load does not always increase stroke volume. However, in patients with acute respiratory failure due to insufficiently corrected hypovolemia, there is a decrease in stroke volume index (SVI), which in the presence of tachycardia reduces cardiac systole time and, consequently, robs coronary blood flow, leading to reduced myocardial contraction [9]. Therefore, extended dynamic monitoring of hemodynamic parameters in patients with acute respiratory failure is an extremely important tool for assessing the tolerability of MV parameters during weaning.

Turton P. and co-authors found that both insufficient diaphragm thickening fraction and excessively high rates indicate a high risk of prolonged artificial lung ventilation [10], and diaphragm thickening fraction in children is less than $17 \%$ according to Lee E.-P. and co-authors [11] is a marker of unsuccessful weaning from MV.

Study limitations. As limitations of the study should be considered a small number of patients and the lack of their division into age subgroups. The absence of such a restriction could increase the representativeness of the results obtained in age subgroups, taking into account the anatomical and physiological characteristics of patients.

Prospects for further research. Further research should be aimed at examining the results of AV weaning 
among a larger cohort of patients, taking into account the age periodization of children.

\section{Conclusions}

The level of transthyretin and SVI in addition to the indicators of the thickening fraction of the right dome of the diaphragm and $\mathrm{CI}$ in children with hypoxemic ARF and the amplitude of movements of the left dome of the diaphragm, $\mathrm{SpO}_{2} / \mathrm{FiO}_{2}$ and transthyretin/C-reactive protein in children with hyperapnic-hypoxemic ARF may affect the results of weaning from MV. Thus, acute malnutrition, together with diaphragmatic dysfunction and hyperdynamic type of circulation, reduce the likelihood of successful MV withdrawal and affect the final clinical outcome in children with various forms of respiratory failure.

\section{Conflict of interest} of interest.

\section{References}

1. Yoshida, T., Uchiyama, A., Matsuura, N., Mashimo, T., Fujino, Y. (2012). Spontaneous breathing during lung-protective ventilation in an experimental acute lung injury model: high transpulmonary pressure associated with strong spontaneous breathing effort may worsen lung injury. Critical Care Medicine, 40 (5), 1578-1585. doi: http://doi.org/10.1097/ccm.0b013e3182451c40

2. Koh, J. W. J. C., Wong, J. J.-M., Sultana, R., Wong, P. P. C., Mok, Y. H., Lee, J. H. (2017). Risk factors for mortality in children with pneumonia admitted to the pediatric intensive care unit. Pediatric Pulmonology, 52 (8), 1076-1084. doi: http://doi.org/ 10.1002/ppul.23702

3. Abdo, M., Talat, M., Zamzam, S. (2014). Difficult weaning from mechanical ventilation in the pediatric ICU. Ain-Shams Journal of Anaesthesiology, 7 (1), 76-79. doi: http://doi.org/10.4103/1687-7934.128423

4. Nitta, K., Okamoto, K., Imamura, H., Mochizuki, K., Takayama, H., Kamijo, H. et. al. (2019). A comprehensive protocol for ventilator weaning and extubation: a prospective observational study. Journal of Intensive Care, 7 (1). doi: http://doi.org/10.1186/ s40560-019-0402-4

5. Turton, P., ALAidarous, S., Welters, I. (2019). A narrative review of diaphragm ultrasound to predict weaning from mechanical ventilation: where are we and where are we heading? The Ultrasound Journal, 11 (1). doi: http://doi.org/10.1186/s13089-019-0117-8

6. Porhomayon, J., Papadakos, P., Nader, N. D. (2012). Failed Weaning from Mechanical Ventilation and Cardiac Dysfunction. Critical Care Research and Practice, 2012, 1-6. doi: http://doi.org/10.1155/2012/173527

7. Boles, J.-M., Bion, J., Connors, A., Herridge, M., Marsh, B., Melot, C. et. al. (2007). Weaning from mechanical ventilation. European Respiratory Journal, 29 (5), 1033-1056. doi: http://doi.org/10.1183/09031936.00010206

8. Porhomayon, J., Papadakos, P., Nader, N. D. (2012). Failed Weaning from Mechanical Ventilation and Cardiac Dysfunction. Critical Care Research and Practice, 2012, 1-6. doi: http://doi.org/10.1155/2012/173527

9. Routsi, C., Stanopoulos, I., Kokkoris, S., Sideris, A., Zakynthinos, S. (2019). Weaning failure of cardiovascular origin: how to suspect, detect and treat - a review of the literature. Annals of Intensive Care, 9 (1). doi: http://doi.org/10.1186/s13613-019-0481-3

10. Yi, L., Liu, Z., Qiao, L., Wan, C., Mu, D. (2017). Does stroke volume variation predict fluid responsiveness in children: A systematic review and meta-analysis. PLOS ONE, 12 (5), e0177590. doi: http://doi.org/10.1371/journal.pone.0177590

11. Lee, E.-P., Hsia, S.-H., Hsiao, H.-F., Chen, M.-C., Lin, J.-J., Chan, O.-W. et. al. (2017). Evaluation of diaphragmatic function in mechanically ventilated children: An ultrasound study. PLOS ONE, 12 (8), e0183560. doi: http://doi.org/10.1371/journal. pone. 0183560

Received date 04.08.2020

Accepted date 11.09.2020

Published date 30.09.2020

Olha Filyk, PhD, Associate Professor, Department of Anesthesiology and Intensive Care, Danylo Halytsky Lviv National Medical University, Pekarska str., 69, Lviv, Ukraine, 79010

E-mail: filyk_olha@meduniv.lviv.ua 